\title{
BMJ Open Feasibility and acceptability of training community health workers in ear and hearing care in Malawi: a cluster randomised controlled trial
}

\author{
Wakisa Mulwafu, ${ }^{1}$ Hannah Kuper, ${ }^{2}$ Asgaut Viste, ${ }^{3}$ Frederik K Goplen ${ }^{3}$
}

To cite: Mulwafu W, Kuper $\mathrm{H}$, Viste A, et al. Feasibility and acceptability of training community health workers in ear and hearing care in Malawi: a cluster randomised controlled trial. BMJ Open 2017;7:e016457. doi:10.1136/ bmjopen-2017-016457

- Prepublication history for this paper is available online. To view these files please visit the journal online (http://dx.doi. org/10.1136/bmjopen-2017016457).

Received 21 February 2017

Revised 6 July 2017

Accepted 2 August 2017

\section{CrossMark}

${ }^{1}$ Department of Surgery, College of Medicine Blantyre Malawi,

Blantyre, Malawi

${ }^{2}$ Department of Clinical

Research, The London School

of Hygiene \& Tropical Medicine, London, UK

${ }^{3}$ Haukeland

Universitetssjukehus, Bergen, Norway

Correspondence to

Dr Wakisa Mulwafu;

wakisamulwafu@gmail.com

\section{ABSTRACT}

Objective To assess the feasibility and acceptability of training community health workers (CHWs) in ear and hearing care, and their ability to identify patients with ear and hearing disorders.

Design Cluster randomised controlled trial (RCT).

Setting Health centres in Thyolo district, Malawi.

Participants Ten health centres participated, 5 intervention (29 CHWs) and 5 control (28 CHWs). Intervention Intervention CHWs received 3 days of training in primary ear and hearing care, while among control CHWs, training was delayed for 6 months. Both groups were given a pretest that assessed knowledge about ear and hearing care, only the intervention group was given the posttest on the third day of training. The intervention group was given 1 month to identify patients with ear and hearing disorders in their communities, and these people were screened for hearing disorders by ear, nose and throat clinical specialists.

Outcome measures Primary outcome measure was improvement in knowledge of ear and hearing care among CHWs after the training. Secondary outcome measures were number of patients with ear or hearing disorders identified by $\mathrm{CHWs}$ and number recorded at health centres during routine activities, and the perceived feasibility and acceptability of the intervention.

Results The average overall correct answers increased from $55 \%$ to $68 \%$ ( $95 \%$ Cl 65 to 71 ) in the intervention group $(p<0.001)$. A total of 1739 patients with potential ear and hearing disorders were identified by $\mathrm{CHWs}$ and 860 patients attended the screening camps, of whom 400 had hearing loss (73 patients determined through bilateral fail on otoacoustic emissions, 327 patients through audiometry). Where cause could be determined, the most common cause of ear and hearing disorders was chronic suppurative otitis media followed by impacted wax. The intervention was perceived as feasible and acceptable to implement.

Conclusions Training was effective in improving the knowledge of CHW in ear and hearing care in Malawi and allowing them to identify patients with ear and hearing disorders. This intervention could be scaled up to other CHWs in low-income and middle-income countries.

Trial registration number Pan African Clinical Trial Registry (201705002285194); Results.
Strengths and limitations of this study

- Structured framework was used to assess the feasibility and acceptability of the intervention to train community health workers (CHWs) in primary ear and hearing care.

- The training and screening camps were led by an ear, nose and throat surgeon, and drew on tools prepared by the WHO

- Through focus group discussions with CHWs, we explored the reasons why people did not attend at the screening camp. In-depth interviews with people who did not attend screening camps could have provided additional information.

- Roles and responsibilities of CHWs is different in different countries. Therefore, generalisation of these findings to other settings must be done with caution.

- Although the cost of the training is reported, the full cost of the intervention, taking into account costs of referrals and final treatment, was not assessed.

\section{INTRODUCTION}

Hearing loss is the most common sensory disability and its prevalence is increasing globally with population ageing. ${ }^{1}$ According to the WHO, an estimated 360 million people, or $5.3 \%$ of the world's population, are living with disabling hearing impairment. ${ }^{2}$ Data for sub-Saharan Africa are sparse, but the prevalence of hearing impairment may be even higher in this region. ${ }^{3}$ The leading causes of hearing impairment in sub-Saharan Africa are believed to be middle ear disease and impacted wax, and are therefore easily amenable to treatment and prevention. ${ }^{4}$

Ear and hearing problems can cause life-long difficulties. They may have profound effect on the ability of individuals to communicate with others, on their education and on their ability to obtain and keep employment. ${ }^{5}$ Furthermore, hearing loss also impacts negatively on social relationships and may lead to stigmatisation. ${ }^{6}$ Consequently, ear and hearing problems 
are likely to produce substantial economic burdens on individuals, communities and countries. ${ }^{7}$

The high prevalence of ear diseases and hearing loss in sub-Saharan Africa is at least partly due to the severe shortage of health workers including audiologists and of resources for hearing aid provision, support and aural rehabilitation programmes. ${ }^{8}$ Educating community health workers (CHWs) about ear disease and hearing loss can help to fill these gaps in settings with a scarcity of specialist health workers. CHWs are members of the communities where they work, selected by the communities, answerable to the communities for their activities and have shorter training than specialist health workers. ${ }^{9}$

The role of CHWs may be particularly important in controlling ear and hearing problems. Effective interventions against ear and hearing problems include ear wax removal, treatment of chronic suppurative otitis media and provision of hearing aids. These interventions can be implemented at the primary level by trained CHWs and have the potential for a major impact on the burden of ear disease and hearing loss when used on a large scale. ${ }^{10}{ }^{11}$ However, most low-income and middle-income countries do not have CHWs trained in primary ear and hearing care (PEHC). ${ }^{12}$

Malawi is a setting where CHWs can potentially make an important contribution to controlling ear and hearing problems. There are only 2 ear, nose and throat (ENT) surgeons for a population of $>17$ million, and only 25 ENT clinical officers. ${ }^{13}$ Data are limited, but a study among children showed a high prevalence of hearing loss, with an estimated 1800 children per million population with hearing impairment from avoidable causes that could be treated through provision of basic primary-level ear and hearing care, in particular wax and middle ear disease. ${ }^{14}$

The aim of this study was to assess the feasibility and acceptability of training CHWs to provide primary-level ear and hearing care, including: identification of patients with ear and hearing disorders, referral of patients to services and treatment of simple ear conditions.

\section{METHODS}

\section{Ethical approval}

Ethical approval was provided by the College of Medicine Research Ethics Committee in Malawi. The study was evaluated and found exempt from review by the Norwegian Regional Committee for Medical and Health Research Ethics (2016/1472 REC South East, Section D).

\section{Study design}

An intervention study was undertaken to assess the feasibility and acceptability of training CHWs in PEHC. A group of CHW were selected, and half the participants were randomised to receive training in PEHC, while for the remainder training was delayed for 6 months.

\section{Study outcomes}

Primary outcome measure was improvement in knowledge of ear and hearing care among CHWs after the training. CHWs were given 60 multiple choice questions from the first six modules of the WHO Primary Ear and Hearing Care Trainer's Manual. ${ }^{15}$ Secondary outcome measures were number of patients with ear or hearing disorders identified by CHWs and number recorded at health centres, and the perceived feasibility and acceptability of the intervention. The records at the health centres were examined at baseline (before training) and after training, the records were examined at 3 months and 6 months.

\section{SETTING}

Thyolo district was selected as the study area. Thyolo is a tea-growing district with a population of approximately 460 000, mainly Lomwe people. It is situated about $30 \mathrm{~km}$ away from Blantyre, where the only dedicated ENT Unit in Malawi is located. The district hospital is one of eight district hospitals which has an ENT clinical officer, who has been working in Thyolo for 2 years. Within this district there are 33 health centres. Each health centre is supported by about $10 \mathrm{CHWs}$ and serves a catchment area of approximately 14000 people.

\section{SUBJECTS}

CHWs were selected among Malawian Health Surveillance Assistants, which is the formal cadre of CHWs in Malawi. These form a cadre of 10500 frontline health workers employed by the Ministry of Health and comprise $30 \%$ of the health workforce in Malawi. ${ }^{16}$ Each health surveillance assistant in Malawi is assigned to a catchment area of approximately 1000 inhabitants and its associated health facility, covering a radius of $8 \mathrm{~km}$ except in district-defined hard-to-reach catchment areas. They track pregnancies, births and deaths using their village health registers, conduct health talks and vaccinations. Each receives 12 weeks of training and has important roles in providing care, promoting community participation in healthcare activities and in promoting disease surveillance services at the community level. Prior to this study, they had not received any training in $\mathrm{PEHC}$.

A list of all the 33 health centres together with all the names of the CHWs in Thyolo district was compiled with the help of the District Health Environmental Office in Thyolo district. Using a random number generator, we selected 10 health centres for inclusion in the trial (figure 1); we then randomly allocated 5 health centres to the intervention group and 5 health centres to the control group. Using the random number generator, we selected 6 CHWs (out of approximately 10 CHWs) per health centre. Consequently, a total of 30 intervention CHWs and 30 control CHWs were selected. 
Figure 1: Flow of participants through the study

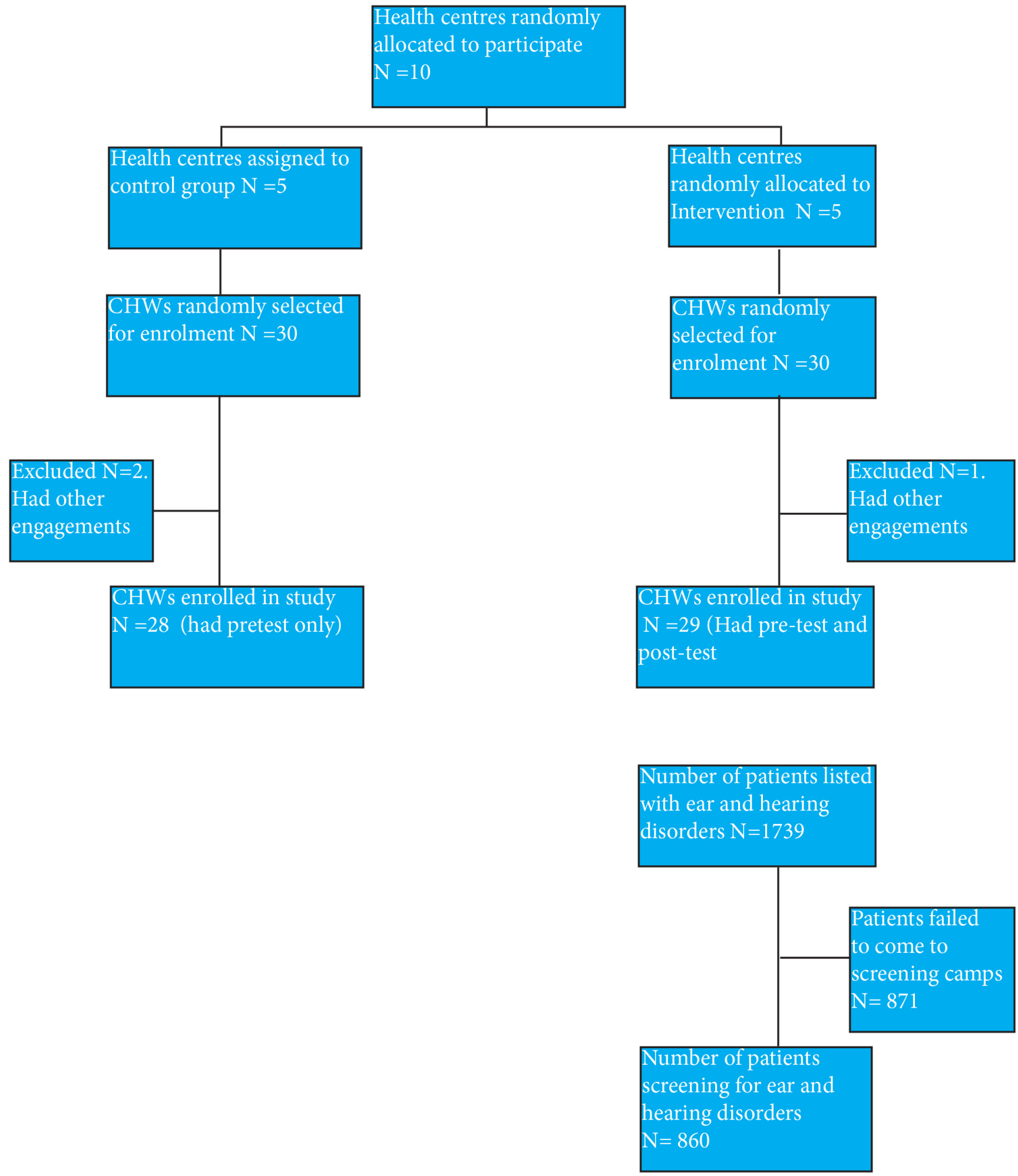

Figure 1 Flow of participants through the study.

\section{Consent and pretest}

The selected CHWs were called up for a briefing at a central location, with intervention and control groups meeting separately. They were briefed on the study and written consent was taken from them to be part of the study after they had received details of what participation involved. Data collected from the CHWs included age, sex and years of formal education. They were administered a 
pretest questionnaire containing the questions from the first six modules of the intermediate-level WHO Primary Ear and Hearing Care Trainer's Manual (10 questions per module). ${ }^{15}$ The participants in the control group were assured of the training after 6 months.

\section{Training for intervention group}

The training lasted 3 days and was undertaken by an ENT surgeon and two ENT clinical officers. The two ENT clinical officers each had 18 months of training in ENT and had participated in a PEHC course. A training curriculum and manual was developed in English by local experts (one audiologist, three audiological officers, three ENT clinical officers and one ENT surgeon). The training manual was based on both the Basic and Intermediate Manual of WHO Primary Ear and Hearing Care Training Resources. ${ }^{15}$

The first part of the training focused on knowledge about ear and hearing disorders. Training emphasised the structure and function of the ear, causes of hearing impairment and their management and levels of hearing impairment. Next, the training focused on skills training, including: (1) history taking in patient with ear and hearing disorders, (2) ear examination, (3) steps in doing otoscopy, (4) steps in doing voice tests and (5) assessment of hearing in children. Training methods included lectures, posters of ear and hearing disorders, flip charts, demonstrations, practical of voice tests, discussion and group work. Training was done both in English and Chichewa (national language of Malawi). At the end of the training, each CHW was given a training manual that contained the key points of training and which could be referred to when needed. They were also given Arclight otoscopes (WJW Ltd, Liverpool, UK), to allow ear examination.

The participants were given a posttest questionnaire on the third day of training, using the same questionnaire as in pretest. The participants were also asked how their opinions about the length of training and whether or not they felt comfortable in identifying people with ear and hearing disorders.

\section{MOBILISATION OF PATIENTS BY COMMUNITY HEALTH WORKERS}

After training, each CHW in the intervention group was given 1 month to identify, list and refer patients with suspected ear and hearing disorders from their own village to their corresponding health centre. First, the CHW met with the village headman, village development committee members and village health committee members to explain in detail about the programme. Next, the CHW met with the community members to explain about the programme and to schedule dates for screening of the community members. CHWs were asked to use multiple methods in their identification (door to door, school screenings, health education and church/mosque announcements). CHWs took history, did otoscopy and voice tests as a way of identifying community members with ear and hearing disorders. CHWs created a list of patients they suspected of having ear and hearing disorders in their community.

Identified patients with suspected ear disorder or hearing loss were asked to come to the scheduled screening camps, which took place at the five health centres of Bvumbwe, Chimaliro, Chisoka, Changata and Gombe.

\section{SCREENING CAMPS}

The listed patients were asked to come to the health centre in their catchment area together with their CHW. A team of six people (1 ENT surgeon, 1 ENT clinical officer, 2 Queen Elizabeth Central Hospital (QECH) audiological officers and 2 research assistants) from the ENT Department at QECH in Blantyre travelled to all the five health centres in Thyolo to conduct the screening camps.

All patients underwent otoscopy, pure tone audiometry, transient evoked otoacoustic emissions (TEOAEs) and tympanometry performed by one of two audiological officers.

- Otoscopy was performed on all patients using the Heine Mini 2000 (HEINE Optotechnik, Herrsching, Germany).

- Audiometry was performed in all patients aged $>4$ years who were able to cooperate in a quiet room using the KUDUwave 5000 audiometer (eMoyoDotnet (Pty) Ltd, Randburg, South Africa). Thresholds were obtained at frequencies of. 5, 1, 2 and $4 \mathrm{kHz}$ according to WHO recommendations. Pure tone average (PTA) was calculated based on these four frequencies. Hearing impairment was defined as PTA $>25 \mathrm{~dB}$ in the better ear.

- TEOAEs were measured in subjects aged $<4$ years and those who were not able to cooperate for audiometry. TEOAEs were tested using the Sentiero handheld device (PATH Medical Solutions, Guymark, UK) and assessed in each ear at frequencies between 1000 and $4000 \mathrm{kHz}$. Results were graded as 'pass' (indicating normal hearing) or 'fail' (indicating impaired hearing).

- Tympanometry was done in all patients using Tympanometer S/N P 99 0556, Grason-Stadler, USA.

Data was recorded on the WHO/Prevention of Blindness and Deafness (PBD) Ear and Hearing Disorders Survey Form.

Patients with ear wax had this removed on site by ENT clinicians. Those with discharging ears had ear toilet and were given ciprofloxacin ear drops. Those with bigger wet perforations had candiderm (beclomethasone dipropionate, clotrimazole and gentamicin sulfate) inserted in the middle ear. All patients with chronic otitis media (active or inactive) were referred to QECH.

Recorded data of patients with ear and hearing disorders at the health centres were collected at baseline (1 month 
data before the study), at 3 months and 6 months after intervention.

\section{Qualitative data collection}

We used the consolidated criteria for reporting qualitative studies' checklist to report our methods and results. ${ }^{17}$ Focus group discussions (FGDs) were undertaken by a female research assistant in three of the five health centres (Chimaliro, Bvumbwe and Chisoka). In each health centre, we chose a quiet room where the discussion were conducted. The CHWs involved in the FGDs were purposively selected. There were a total of 17 CHWs (9 women and 8 men) who participated in the three FGDs, each including 5-6 participants. The female research assistant was not involved in quantitative data collection or analysis to reduce the possibility of bias. We conducted the FGDs using semistructured interview guide. The guided discussions asked CHWs about their impressions on training, and challenges faced when identifying people with ear and hearing disorders. Each FGDs took approximately $45 \mathrm{~min}$. The discussions were in Chichewa. FGDs were audio recorded.

\section{DATA ANALYSIS}

Data were analysed using Stata V.13. Tests for normality were done using SPSS V.21. All the scores were tested for normal distribution using the Shapiro-Wilk test. We conducted an independent t-test to determine the difference in the mean knowledge scores between the intervention and control groups and paired t-test in the intervention group before and after the training. For all procedures, alpha was set at 0.05 . A paired t-test and $\mathrm{X}^{2}$ statistic were used to compare number of patients seen at baseline in the health centres to those seen at 3 months and 6 months in both intervention and control groups.

Transcripts from each FGDs were generated and translated into English, and those transcripts were examined for recurring themes and patterns through open coding and qualitative content analysis. NVivo 11 was used for coding the data.

\section{RESULTS}

A total of 57 CHWs were included, 28 in the control arm and 29 in the intervention arm. Intervention and control CHWs were similar in terms of proportion of men $(59 \%$ vs $54 \%$ ), mean age (37 years, range $28-51$ vs 38 years, range 29-55), and proportion who had $\geq 10$ years of formal education ( $56 \%$ vs $54 \%$ ).

Test scores are shown in table 1 . In the pre-test questionnaire, the intervention group scored slightly lower (55\%, $95 \%$ CI $52 \%$ to $58 \%$ ) compared with the control group (58\%, $95 \%$ CI $56 \%$ to $60 \%$; $p<0.05)$. After training, the mean score for the posttest in the intervention group increased to $68 \%$ (95\% CI $65 \%$ to $71 \%$ ), showing a statistically significant improvement from baseline $(\mathrm{p}<0.001)$. There was also improvements in knowledge for the individual modules, except for the module on the inner ear, and assessment and counselling.

The majority of the CHWs (67\%) said that the length of the training was right, whereas $33 \%$ thought that it was too short. In dealing with patients with ear and hearing disorders, $52 \%$ reported that they felt comfortable and $48 \%$ felt very comfortable after the training. None of the CHWs reported feeling uncomfortable. Overall, the average cost of training one CHW was $\$ 189$, including trainer's costs (\$33), trainee's stipend (\$64), training supplies (\$61) and travel costs $(\$ 31)$.

After training, the CHWs identified and referred a total of 1739 patients with suspected ear disorder or hearing loss. Of these, only 860 patients $(49 \%)$ attended the screening camp. Of those attending, $67.2 \%$ were women and the mean age was 23 years (range 2 months- 90 years).

TEOAEs were obtained for subjects $<4$ years and those who were not able to cooperate for audiometry. Out of 860 patients attending the screening camp, 249

Table 1 Proportion of CHWs who answered correctly in the six different modules

\begin{tabular}{|c|c|c|c|c|}
\hline \multirow[b]{2}{*}{ Module } & \multicolumn{3}{|c|}{ Proportion of questions answered correctly } & \multirow[b]{2}{*}{$\begin{array}{l}\text { Significance (paired } \\
\text { t-test pretest vs posttest) }\end{array}$} \\
\hline & $\begin{array}{l}\text { Control group } \\
\text { pretest }(n=28)\end{array}$ & $\begin{array}{l}\text { Intervention group } \\
\text { pretest }(n=29)\end{array}$ & $\begin{array}{l}\text { Intervention } \\
\text { group } \\
\text { posttest }(n=29)\end{array}$ & \\
\hline Structure and function of the ear & $58 \%$ & $61 \%$ & $82 \%$ & $<0.0001$ \\
\hline $\begin{array}{l}\text { Hearing impairment and deafness: } \\
\text { causes and prevention }\end{array}$ & $52 \%$ & $53 \%$ & $78 \%$ & $<0.0001$ \\
\hline $\begin{array}{l}\text { The ear canal: examine, diagnose and } \\
\text { clean }\end{array}$ & $54 \%$ & $47 \%$ & $57 \%$ & 0.03 \\
\hline $\begin{array}{l}\text { The middle ear: examine, diagnose and } \\
\text { treat }\end{array}$ & $55 \%$ & $48 \%$ & $52 \%$ & 0.28 \\
\hline Assessing hearing and counselling & $72 \%$ & $69 \%$ & $66 \%$ & 0.17 \\
\hline
\end{tabular}

$\mathrm{CHW}$, community health worker. 
Table 2 Categories of hearing impairment reported as pure-tone average of $0.5,1,2$ and $4 \mathrm{kHz}$ in the better hearing ear among participants attending the screening camp

\begin{tabular}{|c|c|c|c|c|}
\hline & $\begin{array}{l}\text { Children } \\
\text { (<18years) }\end{array}$ & & Adults ( $>18$ & (ears) \\
\hline $\begin{array}{l}\text { Hearing } \\
\text { impairment } \\
\text { category }(\mathrm{dB})\end{array}$ & $\begin{array}{l}\text { Number of } \\
\text { subjects }\end{array}$ & $\%$ & $\begin{array}{l}\text { Number of } \\
\text { subjects }\end{array}$ & $\%$ \\
\hline Normal ( $\leq 25)$ & 149 & 60.3 & 116 & 33.6 \\
\hline Slight (26-40) & 73 & 29.6 & 119 & 34.5 \\
\hline Moderate (41-60) & 19 & 7.7 & 74 & 21.5 \\
\hline Severe (61-80) & 4 & 1.6 & 23 & 6.7 \\
\hline Profound (>80) & 2 & 0.8 & 13 & 3.8 \\
\hline Total & 247 & 100 & 345 & 100 \\
\hline
\end{tabular}

patients had TEOAEs, 592 audiometry and for 19 it was not possible to undertake either audiometry or TEOAE. Out of the 592 patients who underwent audiometry, 327 $(55 \%)$ had hearing impairment defined as PTA $>25 \mathrm{~dB}$ in the better hearing ear (table 2). Of the 265 subjects without hearing impairment according to this definition, 115 had unilateral hearing loss, whereas 152 subjects had normal hearing (PTA $\leq 25 \mathrm{~dB}$ ) in both ears. Of those who underwent TEOAE, 73 patients $(30 \%)$ had bilateral fail. Consequently, of the 841 who were screened, 400 (48\%) were found to have a hearing impairment. The rest had either unilateral hearing loss $(\mathrm{n}=115,14 \%)$, normal hearing but with ear disorders $(n=148,18 \%)$ or normal hearing without an ear disorder $(n=184,22 \%)$.

The causes of ear and hearing disorders were determined by an ENT surgeon and ENT clinical officer (table 3). It was not possible to determine the cause for one in three ears with an ear and hearing disorder for
Table 4 Further actions needed for patients with ear and hearing disorders who attended the screening camp

\begin{tabular}{|c|c|c|c|c|}
\hline \multirow[b]{2}{*}{ Action needed } & \multicolumn{2}{|c|}{ Children (<18years) } & \multicolumn{2}{|c|}{ Adults (>18years) } \\
\hline & Number & $\%$ & Number & $\%$ \\
\hline Medication & 110 & 20.8 & 90 & 22.3 \\
\hline $\begin{array}{l}\text { Hearing aid } \\
\text { evaluation }\end{array}$ & 86 & 16.2 & 146 & 36.2 \\
\hline $\begin{array}{l}\text { Language } \\
\text { and speech } \\
\text { rehabilitation }\end{array}$ & 3 & 0.6 & 0 & 0.0 \\
\hline $\begin{array}{l}\text { Special needs } \\
\text { education }\end{array}$ & 14 & 2.6 & 1 & 0.2 \\
\hline $\begin{array}{l}\text { Vocational } \\
\text { training }\end{array}$ & 4 & 0.8 & 0 & 0.0 \\
\hline \multirow[t]{2}{*}{ Surgery referral } & 49 & 9.2 & 42 & 10.4 \\
\hline & 264 & 49.8 & 124 & 30.8 \\
\hline${ }^{\star}$ Total & 530 & 100 & 403 & 100 \\
\hline
\end{tabular}

${ }^{*}$ Out of total actions (not patients).

adults. For those conditions that we were able to determine the cause, the majority were caused by chronic suppurative otitis media and impacted wax. Impacted wax was removed on site and no further action was required.

Table 4 presents further action required for patients with ear and hearing disorders. The majority of the patients were given medication on the spot, but were asked to be followed up by the ENT clinical officer at the district hospital. Those requiring hearing aid evaluation and surgery referral (mainly for tympanomastoid surgery) were referred to a tertiary hospital of QECH.

Table 5 shows the patients with ear and hearing disorders recorded at the 10 health centres, comparing intervention and control groups at baseline, third and sixth

Table 3 Causes of ear and hearing disorders among participants who attended the screening camp

\begin{tabular}{|c|c|c|c|c|}
\hline & $<18$ years & & $>18$ years & \\
\hline Ear conditions & Total number of ears & $\%$ & Total number of ears & $\%$ \\
\hline Wax & 89 & 9.2 & 122 & 16.2 \\
\hline Foreign body & 8 & 0.8 & 1 & 0.1 \\
\hline Otitis externa & 3 & 0.3 & 1 & 0.1 \\
\hline Acute otitis media & 23 & 2.4 & 11 & 1.5 \\
\hline Chronic suppurative otitis media & 165 & 17.0 & 110 & 14.6 \\
\hline Otitis media with effusion & 36 & 3.7 & 45 & 6.0 \\
\hline Dry perforation & 5 & 0.5 & 14 & 1.9 \\
\hline Infectious diseases & 22 & 2.3 & 8 & 1.1 \\
\hline Genetic diseases & 8 & 0.8 & 3 & 0.4 \\
\hline Non-infectious diseases & 4 & 0.4 & 22 & 2.9 \\
\hline Undetermined causes & 124 & 12.8 & 250 & 33.2 \\
\hline Not tested & 36 & 3.7 & 2 & 0.3 \\
\hline Normal ear and hearing & 445 & 46.0 & 163 & 21.7 \\
\hline Total & 968 & 100.0 & 752 & 100.0 \\
\hline
\end{tabular}


Table 5 Patients with ear and hearing disorders recorded at the 10 health centres

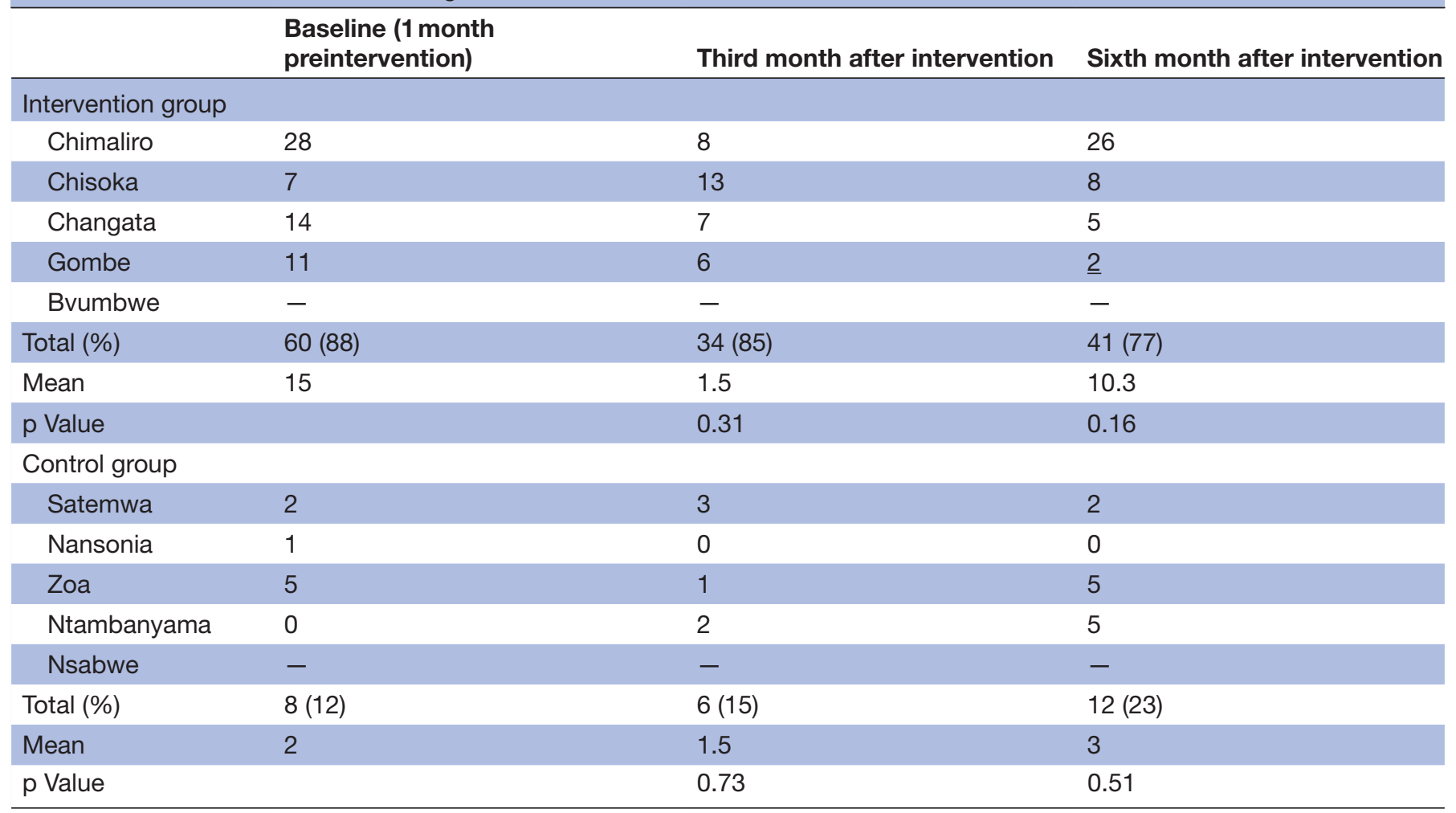

Data were not collected for the two health centres.

months. Although the numbers recorded are small, there were more patients seen at baseline, third month and sixth month in the intervention group as compared with the control group. There was no difference in referral rates at baseline and 3 months or 6 months (paired t-test and $\left.X^{2}: p>0.05\right)$.

\section{FINDINGS FROM FGDS}

Three main themes emerged from the FGDs: training of CHWs and other health workers, identification of patients and problems faced in the mobilisation of patients.

\section{Training of CHWs and other health workers}

Overall, the training was felt to be successful, however there was an expressed need to expand the training for CHWs to include medical assistants and other health workers in health facilities in their areas. As one trainee put it:

It is only a few of us who have received this training, therefore I feel that those other remaining HSA's and other health workers should also get the training, so that the other remaining communities should be assisted

There were issues concerning the complexity of the diagrams used in the training manual, as the participants found these difficult to understand.

Do you see that, these words written about the anatomy of the ear, but when I now come to the real ear and ask what's this? For me to find the part, according to the way the picture looks like, I cannot manage to identify that, because the picture and the real ear are two different things, eeh but, the manual has been helpful.

There was also a request for more practice, rather than theory, particularly with respect to diagnosis of conditions.

'I feel that if only we had trainings where we could also have practicals, it would have been helpful'

\section{Identification of participants}

A number of problems were encountered by the CHWs in the identification of participants with ear disorders or hearing loss and these included failure of the otoscopes, which were solar powered and so reliant on sunshine for charging:

"Like at the beginning, when using the otoscope, maybe you may have prepared to go out for work, you happen to find that it is cloudy, there are showers, whereby you couldn't have charged the device"

On the other hand, other participants were happy with the equipment.

"This work shows that this doesn't require expensive instruments or instruments that are hard to purchase, that's what I observed, those are my views" 
Others reported on particular methods that helped in the identification of patients, such as the involvement of the traditional chief of the village to legitimise the work.

\section{Problems faced with mobilisation of patients for screening camps}

A number of problems were encountered by the CHWs, and these included poor weather conditions, belief in different deities so that people would rather go and receive prayers than meet health personnel, lack of support from the village heads and competing ongoing events that were a distraction (eg, the free distribution of fertiliser coupons).

'Whenever we could go to the field just as my friend has said it, it used to be very hard because whenever we could go to the field and happen to get to the venue, it would be found that people could have gone for registration (for fertilizer coupons) just the way it happens during this time to register for coupons in the village, and were supposed to stay in the village and wait for them'

\section{DISCUSSION}

The primary ear and hearing training increased the knowledge and confidence of CHWs in ear and hearing care, an area of healthcare in which they had not previously been trained. The trained CHW demonstrated their ability to identify patients with ear and hearing disorders, both through outreach and as part of routine practice. They identified 1739 people with potential ear or hearing disorders of whom 860 attended a screening, and almost half (400) had significant hearing loss and a further 115 had unilateral hearing loss. There was little change, however, in the patients with ear and hearing disorders recorded at the health centres after the intervention. The trainees perceived that the intervention was feasible and acceptable. Although the number of CHWs who were trained per health centre was small, these positive findings are encouraging as it can be scaled up. Furthermore, the training was relatively cheap ( $\$ 189$ per CHW trained) and well received by the participants.

Successful integration of ear and hearing care into primary healthcare requires resources, to raise awareness, train CHWs and provide equipment and medications at the health centre. Important lessons can also be learnt from the study and the existing literature in considering whether and how to scale up the primary ear and hearing training.

\section{Were CHW the appropriate target for training?}

This study showed that trained CHWs proved to be a valuable resource in mobilising patients with ear and hearing disorders. This is in contrast to what Kalua et al showed that other community key informants (eg, village volunteers) were much better at identifying blind children than CHWs. ${ }^{18}$ In that study, CHWs reported lack of time as a major constraint in identifying blind children, and it is well known that CHWs are often overloaded with many competing tasks. Although, we did not compare with other cadres of community like village volunteers, we found that the number of patients with potential hearing loss identified by CHWs were still large.

\section{Was the content of the training appropriate?}

There was an improvement in the knowledge of ear and hearing disorders among CHWs overall showing that the training was appropriate. However, there was no improvement in knowledge about the middle ear or assessing hearing and counselling. Further improvement of these modules is needed to ensure that the material is at the right level for CHWs. About 22\% of the patients examined at the screening camps did not have an ear and hearing disorder. We consider this to be a relatively low false-positive rate showing that the CHWs were reasonably competent at identifying people with hearing loss. There is still room for improvement, however, and a further emphasis on future training should focus on normal ear anatomy and more practical sessions on normal ears. The CHWs were trained in otoscopy, but their practical skills were not assessed. The primary aim was to enable them to identify common pathologies like wax and discharge. However, in a possible higher level course in the future, it would be a good idea to test both manual and diagnostic skills.

\section{Was the length of training sufficient?}

Most of the CHWs were happy with the length of the training while few would like it to have been extended. The cost of training of our training was an average of $\$ 189$ per health worker. Kyabayinze et al in Uganda showed that the average cost per health worker of the 1-day training was $\$ 101$ (range $\$ 92-112$ ) with the main cost drivers being trainee travel and per diems. ${ }^{19}$ One of the ways of reducing the cost of training is to reduce the length of the training, which would require further testing. In mental health and blindness, they have successfully conducted 1-day training sessions. ${ }^{20}$ However, reducing the length of training was against the expressed wishes of the CHWs.

\section{Were the CHW able to identify people with ear and hearing disorders?}

CHWs were able to identify people with ear and hearing disorders both within the community and in the clinics. However, the accuracy of diagnosis made by CHWs compared with that of ENT specialist was not measured, which is a limitation.

Although the CHWs were able to identify about 1739 patients, only 860 patients appeared for screening. The major reason given for non-attendance was that most clients went to receive free fertiliser coupons. Other barriers in ear and hearing care need to be explored in more detail and could include difficulties in accessing care, limited engagement of communities and inadequate support from health systems. ${ }^{21}$ Müller et al reported 
that of the 84 trained village health workers in primary eye care, only $13(15 \%)$ brought patients to the health centres and the main reason suggested for the difference was lack of motivation among village health workers. ${ }^{20}$

Resources may be required to pay for transport reimbursements for patients to travel from their villages to the health centre as there is clearly a large unmet need for services among people in the communities.

\section{Were the CHWs appropriately equipped?}

Equipping CHWs with a tool like an Arclight otoscopes may have improved the diagnostic accuracy especially for impacted wax and chronic suppurative otitis media.

There is need to do more research on the provision of diagnostic and therapeutic PEHC services by CHWs and general health workers at frontline health facilities. With the advent of a lot of software applications for audiometry, ${ }^{22}$ there is need to look at the feasibility of equipping the CHWs with the tool. Furthermore, research is needed as to which therapeutic approaches are appropriate at the primary level. For instance, primary healthcare workers are often taught to do dry mopping for wet perforations. Among our patients with wet perforations, a number of them had dead house flies in the ears which may have been difficult to remove with dry mopping alone. Evidence is also needed as to whether or not ear syringing may be useful for these sort of conditions.

In summary, in line with the Malawi Government guidelines on task shifting to $\mathrm{CHWs},{ }^{23}$ the following tasks in ear and hearing care are recommended for CHWs. There are (1) information, education and communication on ear and hearing disorders; (2) identification of cases for referral, (3) follow-up of cases for treatment adherence; (4) support and counselling of families on ear and hearing disorders. All these tasks are based on the assumption that the CHWs have been trained in ear and hearing care and that equipment like otoscopes are made available to them.

There are important strengths to the study. It used a structured framework to assess the feasibility and acceptability of the intervention to train CHW in PEHC. The training and screening camps were led by an ENT surgeon, and drew on tools prepared by the WHO. There are also limitations to consider. It was not possible to explore in detail why people did not attend at the screening camp. We only conducted FGDs with CHWs. In-depth interviews with people who did not attend the screening camps could have provided more information. Furthermore, the impact of training CHW in PEHC on their routine clinical activities was not fully evaluated, nor the impact on the number of diagnoses and referrals made of ear and hearing disorders at the primary care level on reducing the burden at the secondary and tertiary levels. We are aware that roles and responsibilities of CHWs is different in different countries. Therefore generalisation of these findings to other settings must be done with caution.

\section{Conclusions}

The training was effective in improving the knowledge of CHW in ear and hearing care in Malawi and allowing them to identify people in the community requiring ENT services. Based on the success of this study, training of CHWs and their identification of patients with ear and hearing disorders could be scaled up in Malawi and tested in other low-income and middle-income countries.

Contributors WM, HK and FKG: designed the study. HK and FKG: helped with data analysis and drafting of the manuscript. WM: conducted the study in Malawi, did data collection, data analysis and drafting of the manuscript. AV: helped to draft and revise the manuscript. All authors: read and approved the final manuscript.

Funding WM is funded by the NORHED Surgery project and this research is part of the $\mathrm{PhD}$ programme with the University of Bergen. Funding for this research came from the NORHED Surgery project (QZA-0484, MWI-13/0030).

Competing interests None declared.

Ethics approval College of Medicine Research Ethics Committee.

Provenance and peer review Not commissioned; externally peer reviewed.

Data sharing statement The database is available for sharing.

Open Access This is an Open Access article distributed in accordance with the Creative Commons Attribution Non Commercial (CC BY-NC 4.0) license, which permits others to distribute, remix, adapt, build upon this work non-commercially, and license their derivative works on different terms, provided the original work is properly cited and the use is non-commercial. See: http://creativecommons.org/ licenses/by-nc/4.0/

(c) Article author(s) (or their employer(s) unless otherwise stated in the text of the article) 2017. All rights reserved. No commercial use is permitted unless otherwise expressly granted.

\section{REFERENCES}

1. Olusanya BO, Neumann KJ, Saunders JE. The global burden of disabling hearing impairment: a call to action. Bull World Health Organ 2014;92:367-73.

2. World Health Organization. Deafness and hearing loss. Mar 2015 http://www.who.int/mediacentre/factsheets/fs300/en (accessed 05.01.2016).

3. Mulwafu W, Kuper H, Ensink RJ. Prevalence and causes of hearing impairment in Africa. Trop Med Int Health 2016;21:158-65.

4. Westerberg BD, Lee PK, Lukwago L, et al. Cross-sectional survey of hearing impairment and ear disease in Uganda. $J$ Otolaryngol Head Neck Surg 2008;37:1-6.

5. Newton V. Early detection of Hearing Impairment. Community Ear and Hearing Health 2004;1:4.

6. Wallhagen Ml. The stigma of hearing loss. Gerontologist 2010;50:66-75.

7. Sanders M, Houghton N, Dewes O, et al. Estimated prevalence of hearing loss and provision of hearing services in Pacific Island nations. J Prim Health Care 2015;7:5-15.

8. Fagan JJ, Jacobs M. Survey of ENT services in Africa: need for a comprehensive intervention. Glob Health Action 2009;2:1932.

9. World Health Organization. Strengthening the performance of community health workers in primary health care. Geneva: World Health Organization; 1989, Report No: 780.

10. Acuin MA. Addressing ear and hearing problems at primary level. Community Ear and Hearing Health 2012;9:1-2.

11. Emerson LP, Job A, Abraham V. A model for provision of ENT health care service at primary and secondary hospital level in a developing country. Biomed Res Int 2013;2013:1-5.

12. Berg AL, Papri H, Ferdous S, et al. Screening methods for childhood hearing impairment in rural Bangladesh. Int $J$ Pediatr Otorhinolaryngol 2006;70:107-14.

13. Mulwafu W, Nyirenda TE, Fagan JJ, et al. Initiating and developing clinical services, training and research in a low resource setting: the Malawi ENT experience. Trop Doct 2014;44:135-9.

14. Tataryn M, Chokotho L, Mulwafu W, et al. Malawi key informant disabililty project. London: London School For Hygiene and Tropical Medicine, 2013. 
15. World Health Organization. Primary ear and hearing care training manuals. Geneva: World Health Organization, 2006.

16. Makaula $P$, Bloch $P, B$ anda HT, et al. Primary health care in rural Malawi - a qualitative assessment exploring the relevance of the community-directed interventions approach. BMC Health Serv Res 2012;12:328

17. Tong A, Sainsbury P, Craig J. Consolidated criteria for reporting qualitative research (COREQ): a 32-item checklist for interviews and focus groups. Int J Qual Health Care 2007;19:349-57.

18. Kalua $\mathrm{K}, \mathrm{Ng}$ 'ongola $\mathrm{RT}$, Mbewe $\mathrm{F}$, et al. Using primary health care (PHC) workers and key informants for community based detection of blindness in children in Southern Malawi. Hum Resour Health 2012;10:37.

19. Kyabayinze DJ, Asiimwe C, Nakanjako D, et al. Programme level implementation of malaria rapid diagnostic tests (RDTs) use: outcomes and cost of training health workers at lower level health care facilities in Uganda. BMC Public Health 2012;12:291.

20. Müller A, Murenzi J, Mathenge W, et al. Primary eye care in Rwanda: gender of service providers and other factors associated with effective service delivery. Trop Med Int Health 2010;15:529-33.

21. du Toit R, Faal HB, Etya'ale D, et al. Evidence for integrating eye health into primary health care in Africa: a health systems strengthening approach. BMC Health Serv Res 2013;13:102.

22. Bright T, Pallawela D. Validated smartphone-based apps for ear and hearing assessments: a review. JMIR Rehabil Assist Technol 2016;3:e13.

23. Government of Malawi. Guidelines for the management of health surveillance assistants in Malawi. Lilongwe, Malawi: Ministry of Health, 2014. 